\title{
Three-dimensional cone-beam computed tomography for assessment of mandibular changes after orthognathic surgery
}

\author{
Lucia H. S. Cevidanes ${ }^{a}$, L'Tanya J. Bailey ${ }^{b}$, Scott F. Tucker ${ }^{c}$, Martin A. Styner ${ }^{d}$, Andre Mole, \\ Ceib L. Phillips ${ }^{f}$, William R. Proffit ${ }^{g}$, and Timothy Turvey ${ }^{h}$ \\ aPostdoctoral fellow, Department of Orthodontics, School of Dentistry, University of North \\ Carolina, Chapel Hill, NC.
}

${ }^{\text {b} A s s o c i a t e ~ p r o f e s s o r, ~ D e p a r t m e n t ~ o f ~ O r t h o d o n t i c s, ~ S c h o o l ~ o f ~ D e n t i s t r y, ~ U n i v e r s i t y ~ o f ~ N o r t h ~}$ Carolina, Chapel Hill, NC.

${ }^{\mathrm{C}}$ Research assistant, Department of Orthodontics, School of Dentistry, University of North Carolina, Chapel Hill, NC.

${ }^{\mathrm{d}}$ Research assistant professor, Department of Computer Sciences, School of Dentistry, University of North Carolina, Chapel Hill, NC.

eResearch assistant professor, Department of Oral and Maxillofacial Radiology, School of Dentistry, University of North Carolina, Chapel Hill, NC.

${ }^{\mathrm{f}}$ Research professor, Department of Orthodontics, School of Dentistry, University of North Carolina, Chapel Hill, NC.

gKenan professor, Department of Orthodontics, School of Dentistry, University of North Carolina, Chapel Hill, NC.

hProfessor, Department of Oral and Maxillofacial Surgery, School of Dentistry, University of North Carolina, Chapel Hill, NC.

\section{Abstract}

Introduction-The purpose of this study was to assess alterations in the 3-dimensional (3D) position of the mandibular rami and condyles in patients receiving either maxillary advancement and mandibular setback or maxillary surgery only.

Methods-High-resolution cone-beam computed tomography scans were taken of 21 patients before and after orthognathic surgery. Ten patients with various malocclusions underwent maxillary surgery only, and 11 Class III patients received maxillary advancement and mandibular setback. Presurgery and postsurgery 3D models were registered on the surface of the cranial base. A new tool was used for graphical overlay and 3D display with color maps to visually assess the locations and to quantify positional changes in the posterior border of the mandibular rami and condyles between superimposed models.

Results-The average displacements in condylar position were small $-0.77 \mathrm{~mm}(\mathrm{SD}, 0.12 \mathrm{~mm})$ and $0.70 \mathrm{~mm}(\mathrm{SD}, 0.08 \mathrm{~mm}$ ) - for 2-jaw and 1 -jaw surgeries, respectively (not significant, $P>$. 05). All 2-jaw surgery patients had backward rotational displacements of the mandibular rami (mean, $1.98 \mathrm{~mm}$; SD, $1.03 \mathrm{~mm}$ ), with a maximum surface distance change of $\geq 2 \mathrm{~mm}$ in 8 of 11 subjects. For the 1-jaw surgery, all subjects had small backward rotational displacements of the

Copyright $@ 2007$ by the American Association of Orthodontists.

Reprint requests to: Lucia H. S. Cevidanes, Department of Orthodontics, School of Dentistry, 201 Brauer Hall, University of North Carolina, CB\#7450, Chapel Hill, NC 27599-7450; cevidanl@ dentistry.unc.edu.. 
mandibular rami (mean, $0.78 \mathrm{~mm}$; SD, $0.25 \mathrm{~mm}$ ), with only 1 subject having a maximum surface distance change $\geq 2 \mathrm{~mm}$. The difference in mean backward rotational displacement was statistically significant $(P<.01)$.

Conclusions-The visualization of 3D model superimposition clearly identified the location, magnitude, and direction of mandibular displacement. The 3D imaging allowed quantification of vertical, transverse, and anteroposterior ramus displacement that accompanied mandibular, but not maxillary only, surgery.

Changes in condylar position after orthognathic surgery procedures are difficult to identify and predict. ${ }^{1-5}$ Long-term stability studies that maxillary advancement surgery is more stable than 2 -jaw procedures. ${ }^{6-8}$ Although many studies the influence of various surgical techniques on the temporomandibular joint, recent 3-dimenional (3D) reconstructions have greatly contributed to the understanding of forward, backward, transverse, and rotational movements of the distal segment of the mandible. , $3,9,10$ The complex movements during surgery for dentofacial deformities clearly need to be assessed in 3 dimensions to improve stability and reduce symptoms of temporomandibular joint disorder after surgery. ${ }^{11-20}$

$3 \mathrm{D}$ reconstructions of the mandibular rami and condyles have been based on magnetic resonance imaging or computed tomography. $3,9,21,22$ Cone-beam computed tomography (CBCT) scanners with lower radiation doses and lower costs, developed in the late 1990s, have been remarkably useful for their intended craniofacial applications..$^{23,24}$

Our aims in this study were to evaluate new tools for superimposition of 3D models constructed from CBCT images taken before and after orthognathic surgery, and to assess alterations in the 3D position of the mandibular rami and condyles in groups of patients receiving either maxillary advancement and mandibular setback or maxillary surgery only.

\section{MATERIAL AND METHODS}

Twenty-one patients ( 7 male, 14 female; $21.6 \pm 7.9$ years) treated at the Dentofacial Deformities Program at the School of Dentistry, University of North Carolina, were recruited for this study. Informed consent was obtained from all subjects, and the experimental protocols were approved by the Institutional Review Board. CBCT scans were taken 1 week before and 1 week after orthognathic surgery with the NewTom 9000 (Aperio Services, Sarasoto, Fla). Ten patients with various malocclusions underwent maxillary surgery only, and 11 Class III patients received maxillary advancement and mandibular setback.

The imaging protocol was 70-second head CBCT scanning with a field of view of $230 \times 230$ $\mathrm{mm}$. All presurgery CT scans were acquired with the patient in centric occlusion, and the splints were not in place at this acquisition. At 1 week after surgery, the intermaxillary splints were still in place for all patients.

All 3D models were constructed from CBCT images with a voxel dimension of $0.58 \times 0.58$ $\times 0.6 \mathrm{~mm}$. Image segmentation of the anatomic structures of interest and the 3D graphic rendering were done by using the Insight SNAP software. ${ }^{25}$

The presurgery and postsurgery models were registered based on the cranial base. The cranial base structures, unlike the maxilla or the mandible, are not altered by surgery. ${ }^{26}$ The fully automated registration was computed with the MIRIT software. ${ }^{27}$ The Valmet software ${ }^{28}$ was used for both visual and quantitative assessment of the location and magnitude of segmentation differences by using graphical overlays and 3D displays (Fig 1). Valmet uses color maps from blue red that indicate 3D inward or outward displacement. 
Absence of surgical displacement $(0 \mathrm{~mm})$ is indicated by green. The 3D displacements described by the color maps require the results to be interpreted in all 3 planes of space. Blue medial surfaces and red lateral surfaces of the rami of the mandible indicated inward and outward displacements of these surfaces, respectively. Medial surfaces were colored red (outward), and lateral surfaces were colored blue (inward) if there was a medial displacement of the condyles and rami with surgery. Displacements in an anterior direction (advancement) were shown in red on the anterior surfaces (outward) and in blue on the posterior surfaces (inward). Posterior displacements (setback) were shown in red (outward) at the posterior surfaces and blue (inward) at the anterior surfaces.

The specific regions of interest of the mandibular rami models of the presurgery and postsurgery images were the condyles and the posterior border of the rami ${ }^{26}$ (Fig 2). Surface distances were not computed separately for rami anatomic structures anterior to the posterior border because these included the areas of the sagittal split osteotomies. Presurgery and postsurgery surface distances at these regions would not assess displacement but would be mainly due to the surgical cuts. The statistical analysis included independent sample $t$ tests to assess statistical significance of the group differences. The level of significance was set at .05 .

\section{RESULTS}

All patients in both groups had only small condylar displacements. The average displacements in condylar position were $0.77 \mathrm{~mm}(\mathrm{SD}, 0.12 \mathrm{~mm})$ and $0.70 \mathrm{~mm}(\mathrm{SD}, 0.07$ $\mathrm{mm}$ ) for 2-jaw and 1-jaw surgeries, respectively ( $P>.05$; Fig 3, Table). Four of the 2-jaw patients had small lateral condylar displacements as shown in red in the color maps (Fig 4).

All subjects who had maxillary surgery only had small backward surface displacements of the mandibular rami (mean, $0.78 \mathrm{~mm} ; \mathrm{SD}, 0.25 \mathrm{~mm}$ ), with only 1 subject having a maximum surface distance change $\geq 2 \mathrm{~mm}$ (Figs 5 and 6, Table).

All 2-jaw surgery patients had mean backward surface displacements of the mandibular rami (mean, $1.98 \mathrm{~mm}$; SD, $1.03 \mathrm{~mm}$ ), with maximum surface distance changes $\geq 2 \mathrm{~mm}$ in 8 of 11 subjects (Figs 4 and 6, Table). The difference between the 1-jaw and 2-jaw surgeries in mean backward displacement was statistically significant $(P<.01)$.

The average surface distances for all surfaces of the mandibular rami were statistically different when the 2 groups were compared (Fig 7, Table).

The average inward displacement at all surfaces was smaller than the image spatial resolution of $0.6 \mathrm{~mm}$ (Table).

\section{DISCUSSION}

Our findings of precise condylar repositioning in the 2-jaw surgery group were consistent with those of Busby et $\mathrm{al}^{7}$ and Proffit et $\mathrm{al}^{29}$ that mandibular setback is generally more stable with maxillary advancement. The average surface distances at the condyles indicated small posterior and lateral displacements of the condyles for the 2-jaw surgery patients that were not significantly different from the maxillary surgery only patients. Although it is technically more difficult to maintain condylar position with mandibular surgery, it appears that it is possible to do this routinely. It was proposed that precise repositioning of the condyles would ensure stability of the surgical results and reduce temporomandibular joint noxious effects, and might improve postoperative masticatory function, ${ }^{1,5,30}$ but the extent of condylar change that is compatible with normal function postsurgically has not been established. 
Small lateral displacements of the condyles were observed in 4 of the 2-jaw surgery patients, as shown by the outward surface distances $(\geq 2 \mathrm{~mm})$ in the lateral poles of condyles. The displacement of the condyles as measured by the methods used in this analysis might not be significant for 2 reasons: (1) the small magnitude of the surface displacements, and (2) the condyles are in the center axis of rotation relative to their articular fossae as the rami and condyles are surgically repositioned. Future long-term follow-ups will assess whether this rotational displacement was small enough to allow for adaptive remodeling without leading to negative sequelae.

The results of this study refer only to immediate postsurgery findings. Some changes might occur immediately after splint removal, and long-term results will show whether the surgical movements explain long-term stability. Surgical displacements and adaptive responses occur relative to adjacent structures in the craniofacial complex. For this reason, the measurements from $3 \mathrm{D}$ curves and surfaces are not isolated measurements but are determined by the manner of assembly of different parts of the craniofacial complex. The mandibular rotations after surgery might be influenced by maxillary, mandibular, and articular fossae morphology, positioning and interrelationships, and type of maxillary surgical movement. ${ }^{31}$ Stability studies showed that maxillary displacement forward or upward is more stable than maxillary displacement downward. ${ }^{6,29}$ Maxillary displacement downward during 2-jaw surgery would certainly influence mandibular position. The association between maxillary surgeries and the type of mandibular rotation requires further investigation and future longterm follow-up studies of condylar and rami remodeling.

\section{CONCLUSIONS}

We analyzed the complex 3D rotational displacements in 1-jaw and 2-jaw surgeries in this study. The visualization of 3D model superimposition and the surface distance calculation clearly identify the location, magnitude, and direction of mandibular rotations during surgery. The 3D imaging allowed quantification of vertical, transverse, and anteroposterior ramus rotations that accompanied mandibular, but not maxillary only, surgery. Condylar displacement with 2-jaw surgery was not significant when compared with maxillary only surgery. Even if small changes occur, they can be identified with this method.

\section{Acknowledgments}

Supported by NIDCR DE005215-26.

\section{REFERENCES}

1. Bettega G, Cinquin P, Lebeua J, Raphael B. Computer-assisted orthognathic surgery: clinical evaluation of a mandibular condyle repositioning system. J Oral Maxillofac Surg. 2002; 60:27-34. [PubMed: 11757002]

2. Lee W, Park JU. Three-dimensional evaluation of positional change of the condyle after mandibular setback by means of bilateral sagittal split ramus osteotomy. Oral Surg Oral Med Oral Pathol Oral Radiol Endod. 2002; 94:305-9. [PubMed: 12324783]

3. Kawamata A, Fujishita M, Kuniteru N, Kanematu N, Niwa K, Langlais R. Three-dimensional computed tomography evaluation of postsurgical condylar displacement after mandibular osteotomy. Oral Surg Oral Med Oral Pathol Oral Radiol Endod. 1998; 85:371-6. [PubMed: 9574943]

4. Magalhaes AEO, Stella JP, Tahasuri TH. Changes in condylar position following bilateral sagittal split ramus osteotomy with setback. Int J Adult Orthod Orthognath Surg. 1995; 10:137-45.

5. Ueki K, Marukawa K, Nakagawa K, Yamamoto E. Condylar and temporomandibular joint disc positions after mandibular osteotomy for prognathism. J Oral Maxillofac Surg. 2002; 60:1424-32. [PubMed: 12465004] 
6. Bailey LJ, Cevidanes LHS, Proffit WR. Stability and predictability of orthognathic surgery. Am J Orthod Dentofacial Orthop. 2004; 126:273-7. [PubMed: 15356484]

7. Busby BR, Bailey LJ, Proffit WR, Phillips C, White RP Jr. Long-term stability of surgical Class III treatment: a study of 5-year postsurgical results. Int J Adult Orthod Orthognath Surg. 2002; 17:15970.

8. Joslin, AE.; Bailey, LJ.; Ruiz, R.; Proffit, WR. Long-term soft tissue changes following orthodontic and surgical correction of skeletal Class III malocclusions (thesis). University of North Carolina; Chapel Hill: 2004.

9. Chirani RA, Jacq JJ, Meriot P, Roux C. Temporomandibular joint: a methodology of magnetic resonance imaging 3-D reconstruction. Oral Surg Oral Med Oral Pathol Oral Radiol Endod. 2004; 97:756-61. [PubMed: 15184860]

10. Harris MD, Van Sickels JE, Alder M. Factors influencing condylar position after the bilateral sagittal split osteotomy fixed with bicortical screws. J Oral Maxillofac Surg. 1999; 57:650-4. [PubMed: 10368087]

11. Harrell WE Jr, Hatcher DC, Bolt RL. In search of anatomic truth: 3-dimensional digital modeling and the future of orthodontics. Am J Orthod Dentofacial Orthop. 2002; 122:325-30. [PubMed: 12226616]

12. Miller AJ, Koutaro M, Hatcher DC. New diagnostic tools in orthodontics. Am J Orthod Dentofacial Orthop. 2004; 126:395-6. [PubMed: 15470342]

13. Hajeer MJ, Ayoub AF, Millett DT, Bock M, Siebert JP. Three-dimensional imaging in orthognathic surgery: the clinical application of a new method. Int J Adult Orthod Orthognath Surg. 2002; 17:318-30.

14. Parks ET. Computed tomography applications for dentistry. Dent Clin North Am. 2000; 44:371410. [PubMed: 10740774]

15. Mol A. Image processing tools for dental applications. Dent Clin North Am. 2000; 44:299-317. [PubMed: 10740770]

16. Cevidanes LHS, Franco AA, Gerig G, Proffit WR, Slice DE, Enlow DH, et al. Assessment of mandibular growth and response to orthopedic therapy in 3-dimensional magnetic resonance images. Am J Orthod Dentofacial Orthop. 2005; 128:16-26. [PubMed: 16027621]

17. Cevidanes LHS, Franco AA, Gerig G, Proffit WR, Slice DE, Enlow DH, et al. Comparison of relative mandibular growth vectors with high resolution 3-dimensional imaging. Am J Orthod Dentofacial Orthop. 2005; 128:27-34. [PubMed: 16027622]

18. Subsol G, Thirion JP, Ayache N. A scheme for automatically building three-dimensional morphometric anatomic atlases: application to skull atlas. Med Image Anal. 1998; 2:37-60. [PubMed: 10638852]

19. Andresen R, Bookstein FL, Conradsen K, Ersboll BK, Marsh JL, Kreiborg S. Surface-bounded growth modeling applied to human mandibles. IEEE Trans Med Imaging. 2000; 19:1053-63. [PubMed: 11204843]

20. Mitteroecker, P.; Gunz, P.; Bookstein, FL. Semilandmarks in three dimensions.. In: Slice, DE., editor. Modern morphometrics in physical anthropology. Kluwer Academic Publishers; New York: 2005.

21. Khambay B, Nebel JC, Bowman J, Walker F, Hadley D, Ayoub A. 3D stereophotogrammetric image superimposition onto 3D CT scan images: the future of orthognathic surgery. A pilot study. Int J Adult Orthod Orthognath Surg. 2002; 17:331-41.

22. Xia J, Samman N, Yeung RWK, Shen SG, Wang D, Ip HHS, et al. Three-dimensional virtual reality surgical planning and simulation workbench for orthognathic surgery. Int J Adult Orthod Orthognath Surg. 2000; 15:265-82.

23. Mozzo P, Procacci C, Tacconi A, Martini PT, Andreis IA. A new volumetric CT machine for dental imaging based on the cone-beam technique: preliminary results. Eur Radiol. 1998; 8:155864. [PubMed: 9866761]

24. Mah J, Hatcher D. Three-dimensional craniofacial imaging. Am J Orthod Dentofacial Orthop. 2004; 126:308-9. [PubMed: 15356493]

25. Yushkevich, P. [October 24, 2006] ITK-SNAP integration, NLM insight. Available at: http:// www.itk.org/index.htm. 
26. Cevidanes LHS, Bailey LJ, Tucker GR Jr, Styner M, Mol A, Phillips C, et al. Superimposition of 3D cone-beam CT models of orthognathic surgery patients. Dentomaxillofac Radiol. 2005; 34:369-75. [PubMed: 16227481]

27. Maes F, Collignon A, Vandermeulen D, Suetens P. Multimodality image registration by maximization of mutual information. IEEE Trans Med Imaging. 1997; 16:187-98. [PubMed: 9101328]

28. Gerig, G.; Jomier, M.; Chakos, M. Valmet. A new validation tool for assessing and improving 3D object segmentation.. In: Niessen, W.; Viergeuer, M., editors. MICCAI Proceedings of the International Society and Conference Series on Medical Imaging Computing and ComputerAssisted Intervention; October 14-17, 2001. Springer; Utrecht, Netherlands; Berlin: 2001. p. 516-28.

29. Proffit WR, Bailey LJ, Phillips C, Turvey TA. Long-term stability of surgical open-bite correction by Le Fort I osteotomy. Angle Orthod. 2000; 70:112-7. [PubMed: 10832998]

30. Tuinzing DB. Factors influencing condylar position after the bilateral sagittal split osteotomy fixed with bicortical screws. J Oral Maxillofac Surg. 1999; 57:654-5.

31. Kwon TG, Mori Y, Minami K, Lee SH, Sakuda M. Stability of simultaneous maxillary osteotomy for treatment of Class III malocclusion: an analysis of three-dimensional cephalograms. J Craniomaxillofac Surg. 2000; 28:272-7. [PubMed: 11467390] 


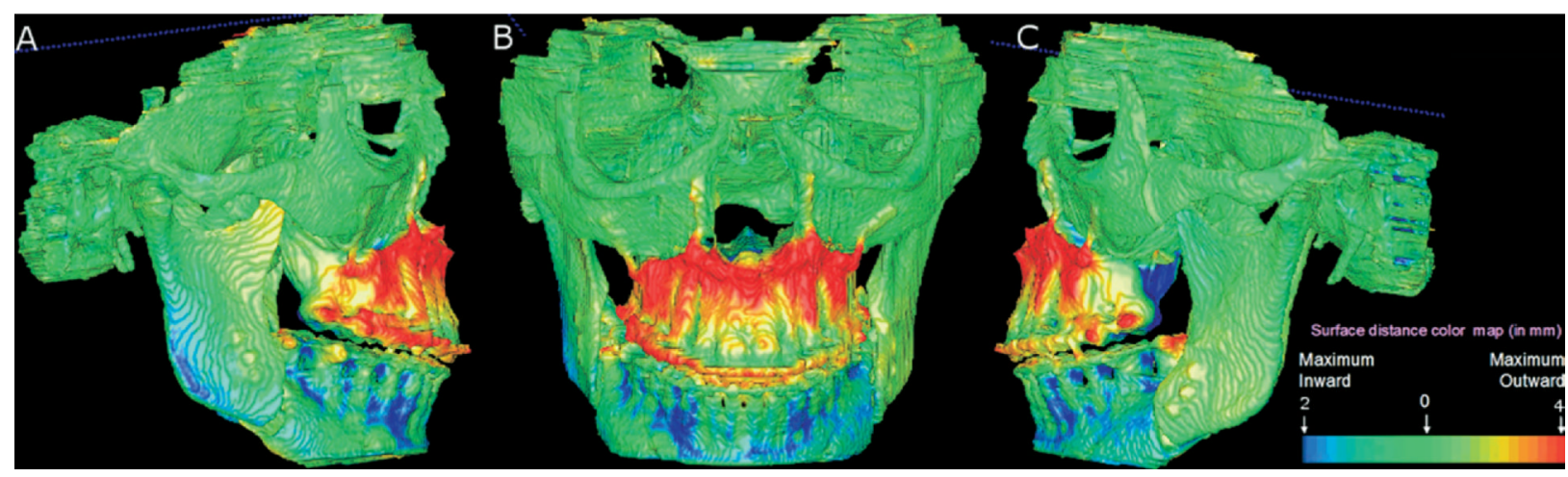

Fig 1.

Superimposition of presurgery and postsurgery models of patient treated with maxillary advancement and mandibular setback. A, Right view; B, frontal view; C, left view. Surface of cranial base was used for registration performed with MIRIT. Cranial base color map is green $(0 \mathrm{~mm}$ surface distance), showing adequate match of before and after models for cranial base structures. 


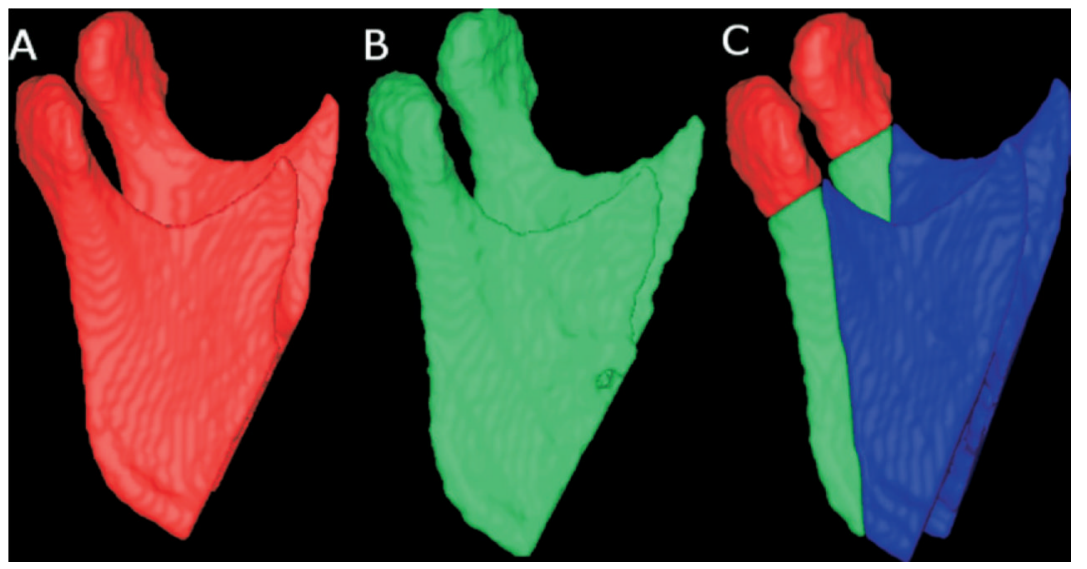

Fig 2.

Lateral views of 3D models of patient. A, 3D model constructed from CBCT image acquired 1-2 weeks before surgery. B, 3D model labeled green constructed from CBCT scan 1 week postsurgery. Other anatomic structures are masked for better visualization of changes in mandibular ramus and condyle. $\mathbf{C}, \mathrm{A}$ and $\mathrm{B}$ are combined after superimposition to identify regions of interest in mandibular rami: condyles (red) and posterior border (green). 


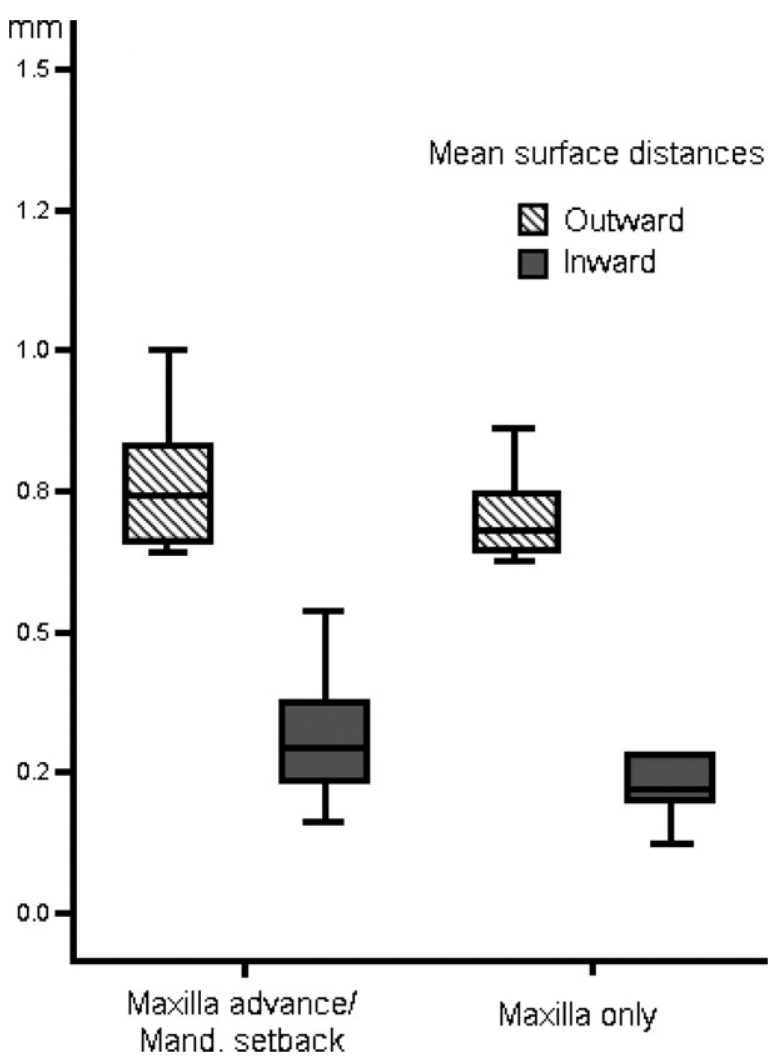

Fig 3.

Average surface distances at condyles for each patient. 


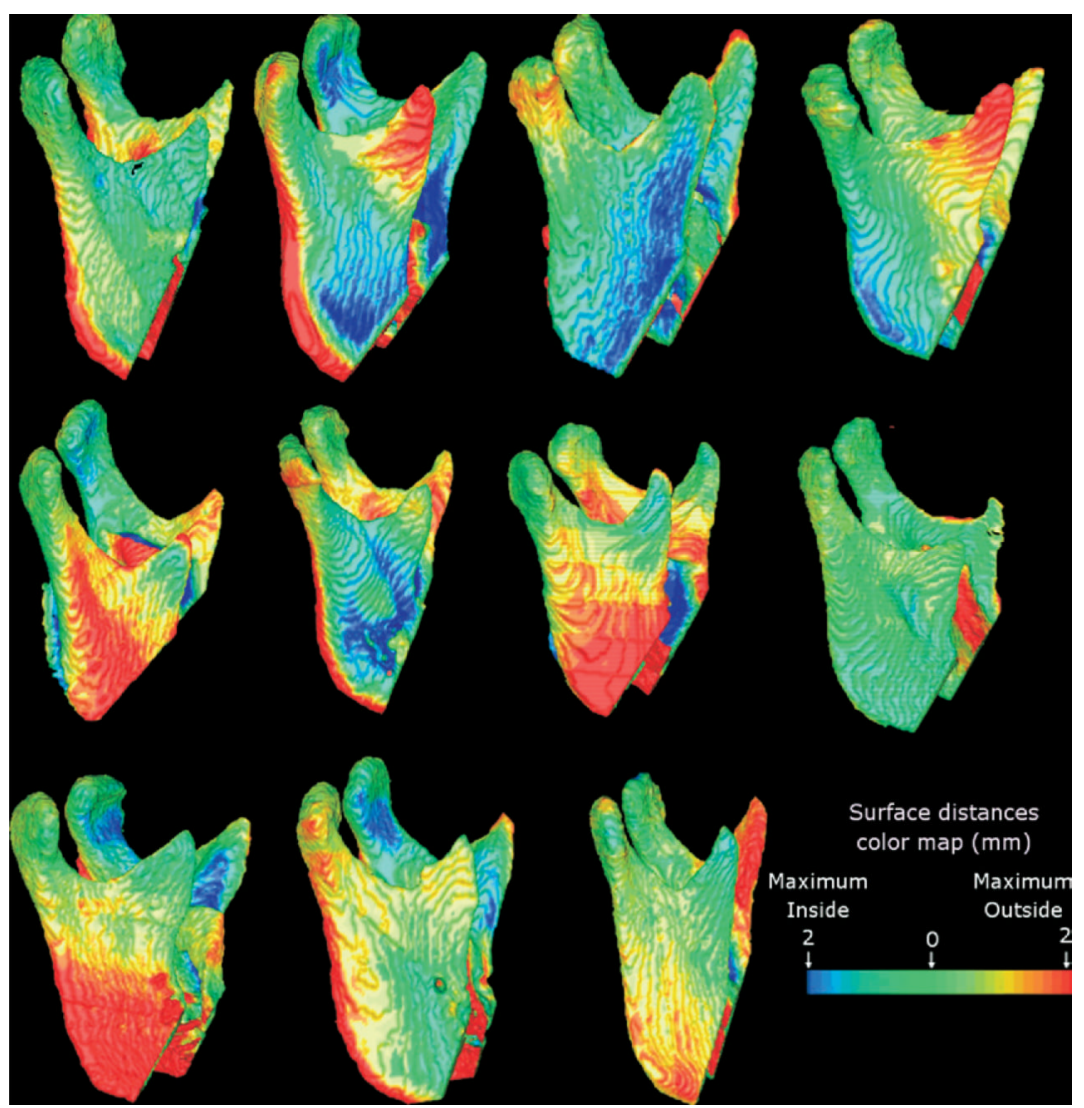

Fig 4.

Eleven patients were treated with maxillary advancement and mandibular setback surgery. Note variability in rotation of rami after bilateral sagittal split osteotomy, with smaller displacement at condyle levels, but surfaces of displacement $\geq 2 \mathrm{~mm}$ along lateral surface and posterior border of rami for 8 of 11 patients. 


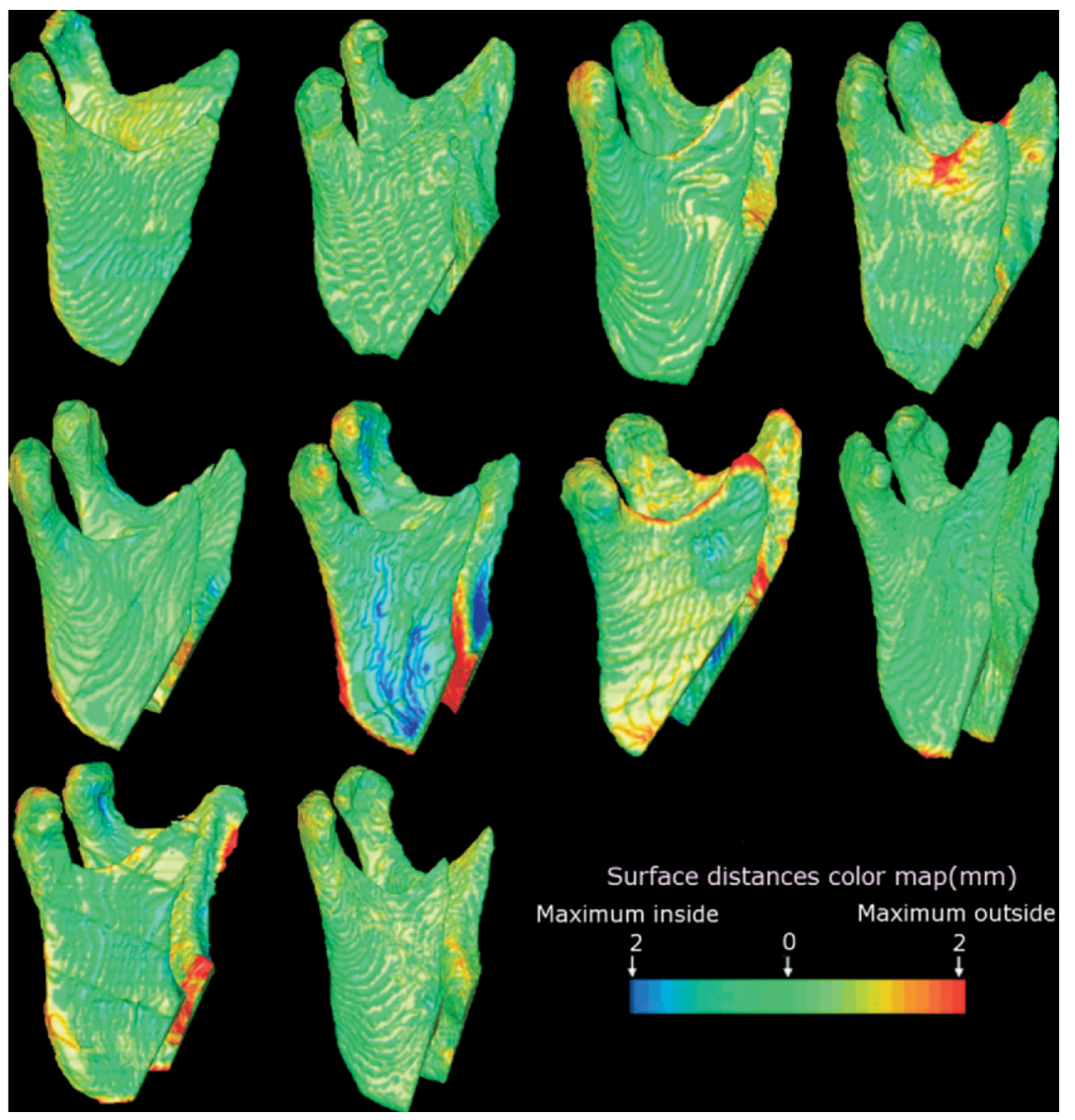

Fig 5.

Ten subjects were treated with maxillary advancement only. Only 1 subject had maximum surface distance change $\geq 2 \mathrm{~mm}$ (red along posterior border of rami). For all other patients, mandibular surface displacements were minimal. 


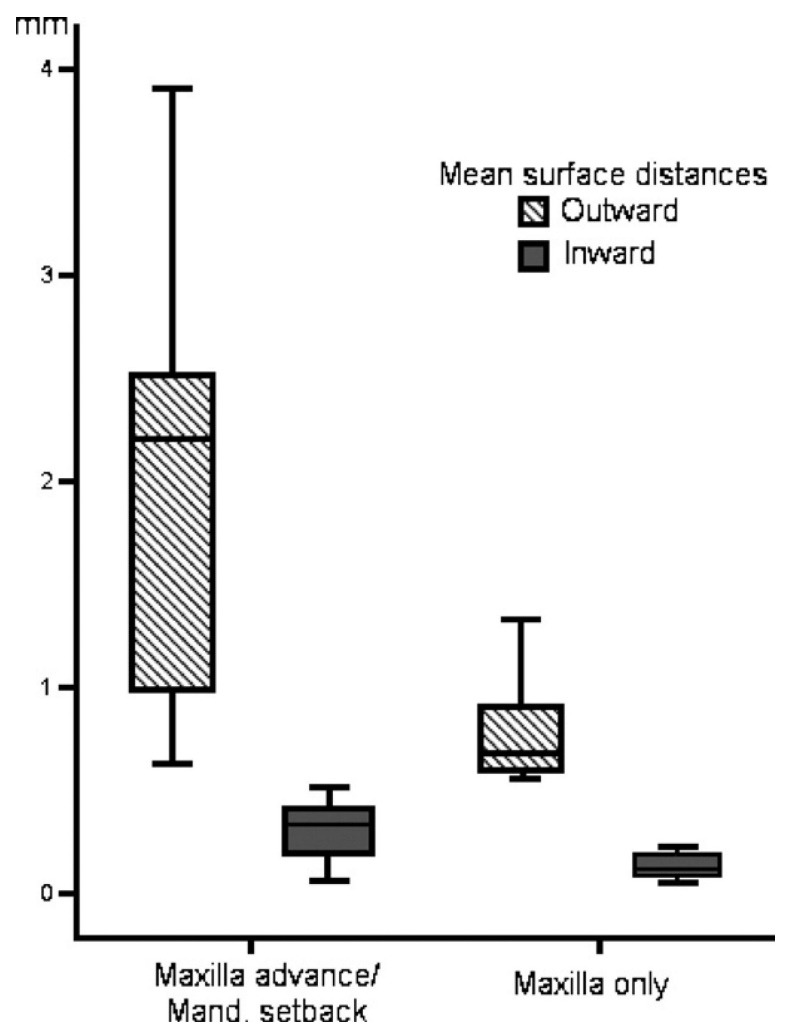

Fig 6.

Average surface distances at posterior border of ramus for each patient. 


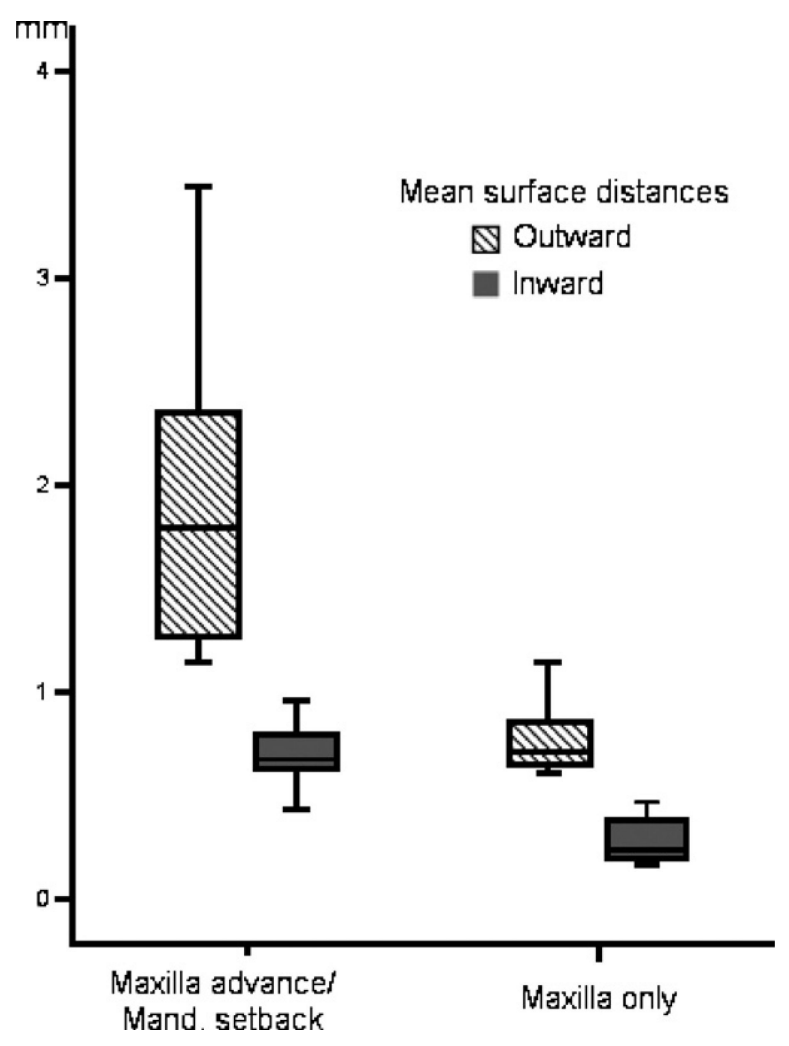

Fig 7.

Overall average surface distances at mandibular rami. 
